EGU2020-12863

https://doi.org/10.5194/egusphere-egu2020-12863

EGU General Assembly 2020

(c) Author(s) 2020. This work is distributed under

the Creative Commons Attribution 4.0 License.

\title{
The role of fault offset in induced seismicity potential
}

\author{
Victor Vilarrasa ${ }^{1,2}$, Francesco Parisio ${ }^{3}$, Roman Makhnenko ${ }^{4}$, Haiqing $\mathrm{Wu}^{2,5}$, and Iman Rahimzadeh \\ $\mathrm{Kivi}^{6}$ \\ ${ }^{1}$ Consejo Superior de Investigaciones Científicas, IDAEA-CSIC, Barcelona, Spain (victor.vilarrasa@idaea.csic.es) \\ ${ }^{2}$ Associated Unit: Hydrogeology Group (UPC-CSIC), Barcelona, Spain \\ ${ }^{3}$ Chair of Soil Mechanics and Foundation Engineering, Technische Universitaet Bergakademie Freiberg, Germany \\ ${ }^{4}$ Department of Civil \& Environmental Engineering, University of Illinois at Urbana-Champaign, USA \\ ${ }^{5}$ Department of Civil and Environmental Engineering (DECA), Universitat Politècnica de Catalunya (UPC), Barcelona, Spain \\ ${ }^{6}$ Department of Petroleum, Gas and Petrochemical Engineering, Shahid Chamran University of Ahvaz (SCU), Ahvaz, Iran
}

Geological media is envisioned as a strategic resource to store large volumes of $\mathrm{CO}_{2}$ and mitigate climate change. Geo-energy applications, such as geologic carbon storage, geothermal energy, and subsurface energy storage, involve injection and extraction of fluids that cause pressure diffusion. Pore pressure changes may induce seismicity, especially in faults that intersect the injection formation or are hydraulically connected with it. We numerically study with finite element analysis of coupled hydro-mechanical conditions how fault stability is affected by fluid injection into a porous aquifer that is overlaid and underlain by low permeability clay-rich formations. We model a layered sedimentary basin with alternating soft and low permeability with stiff and high permeability formations and include the crystalline basement at the bottom. Additionally, a low permeability steep fault, whose offset ranges from zero to the reservoir thickness, crosses the system. We consider a normal faulting stress regime typical of extensional environments. Simulation results show that the reservoir pressurization as a result of fluid injection causes significant stress changes around the fault that affect its stability. The stress changes depend on the stiffness of the rock juxtaposed to the pressurized reservoir. If there is no offset, the rock is stiff on both sides of the fault, inducing a homogeneous horizontal total stress increase along the thickness of the reservoir. As a result, the deviatoric stress becomes smaller and the induced seismicity potential is low. As the fault offset increases, some part of the base rock gets juxtaposed to the pressurized reservoir. The soft base rock deforms more than the reservoir rock in response to the reservoir expansion, inducing a lower horizontal total stress. Thus, fault stability reduces when the pressurized reservoir rock is juxtaposed with the softer base rock. This finding shows that the induced seismicity potential may increase with the fault offset. 